\title{
Habitat fragmentation and biodiversity conservation: key findings and future challenges
}

\author{
Maxwell C. Wilson • Xiao-Yong Chen • Richard T. Corlett • \\ Raphael K. Didham • Ping Ding • Robert D. Holt • Marcel Holyoak • \\ Guang Hu • Alice C. Hughes $\cdot$ Lin Jiang • William F. Laurance • \\ Jiajia Liu - Stuart L. Pimm - Scott K. Robinson - Sabrina E. Russo • \\ Xingfeng Si • David S. Wilcove $\cdot$ Jianguo Wu $\cdot$ Mingjian Yu
}

Received: 5 November 2015/ Accepted: 7 November 2015/Published online: 20 November 2015

(C) Springer Science+Business Media Dordrecht 2015

Habitat loss and fragmentation has long been considered the primary cause for biodiversity loss and ecosystem degradation worldwide, and is a key research topic in landscape ecology (Wu 2013). Habitat fragmentation often refers to the reduction of continuous tracts of habitat to smaller, spatially distinct remnant patches, and habitat loss typically occurs concurrently with habitat fragmentation (Collinge 2009). Although some habitats are naturally patchy in terms of abiotic and biotic conditions (Wu and Loucks 1995), human actions have profoundly

M. C. Wilson · J. Wu

School of Life Sciences, Arizona State University,

Tempe, AZ 85287, USA

e-mail: mcwilso2@gmail.com

X.-Y. Chen

School of Ecological and Environmental Sciences, East

China Normal University, Shanghai 200214, China

R. T. Corlett · A. C. Hughes

Centre for Integrative Conservation, Xishuangbanna

Tropical Botanic Garden, Chinese Academy of Sciences,

Menglun, Mengla 666303, Yunnan, China

R. K. Didham

School of Animal Biology, University of Western

Australia, Perth, WA 6009, Australia

R. K. Didham

CSIRO Land and Water, Centre for Environment and Life

Sciences, Perth, WA 6014, Australia fragmented landscapes across the word (Haddad et al. 2015), altering the quality and connectivity of habitats. Therefore, understanding the causes and consequences of habitat fragmentation is critical to preserving biodiversity and ecosystem functioning.

From May 4th to 10th, 2015, an International Workshop on Habitat Fragmentation and Biodiversity Conservation, held at the Thousand Island Lake, Zhejiang, China, discussed threats to biodiversity in fragmented landscapes and how fragmentation research can identify and help mitigate these threats.

\footnotetext{
P. Ding $(\bowtie) \cdot$ J. Liu $\cdot$ X. Si $\cdot$ M. Yu $(\bowtie)$

College of Life Sciences \& Institute of Ecology, Zhejiang

University, Hangzhou 310058, Zhejiang, China

e-mail: dingping@zju.edu.cn

M. Yu

e-mail: fishmj202@hotmail.com

R. D. Holt

Department of Biology, University of Florida,

Gainesville, FL 32611, USA

M. Holyoak

Department of Environmental Science and Policy,

University of California, Davis, CA 95616, USA

G. $\mathrm{Hu}$

Department of Landscape Architecture, School of Civil Engineering and Architecture, Zhejiang University of Science and Technology, Hangzhou 310018, Zhejiang, China
} 
To meet these challenges, the Workshop had three goals. The first was to synthesize key findings in fragmentation science. Second was to identify important remaining research questions concerning the relationships between habitat fragmentation, biodiversity, and ecosystem functioning at local, regional, and global scales. Finally, we examined the unique roles of field-based fragmentation experiments in addressing these questions. The Workshop's findings are relevant to the broader ecological community, and we present them here to stimulate research that will advance landscape ecology and conservation biology.

\section{Key findings concerning habitat loss and fragmentation}

- While habitat fragmentation ultimately derives from habitat loss, three broadly defined mechanisms mediate the ecological consequences of fragmentation. First, there are those attributable directly to the loss of habitat area. Second, there are those attributable directly to changes in the spatial configuration of the landscape, such as isolation. Finally, there are those attributable to indirect or interaction effects of habitat loss and changes in spatial configuration (Didham et al. 2012), and to the interaction of fragments with the matrix (e.g., spillover effects). A review of the literature found that when one ignores indirect and interaction effects, the impacts of habitat loss are far greater than changing habitat configuration

L. Jiang

School of Biology, Georgia Institute of Technology, Atlanta, GA 30332, USA

W. F. Laurance

Centre for Tropical Environmental and Sustainability

Science, James Cook University, Cairns, QLD 4878,

Australia

W. F. Laurance

College of Marine and Environmental Sciences, James

Cook University, Cairns, QLD 4878, Australia

S. L. Pimm

Nicholas School of the Environment, Duke University, Durham, NC 27708, USA

\section{S. K. Robinson}

Florida Museum of Natural History, University of Florida, Gainesville, FL 32611, USA
(Fahrig 2003); however, newer research suggests that indirect and interaction effects may be the dominant driver of the ecological changes often attributed to habitat loss alone (Didham et al. 2012).

- Species richness often changes significantly with fragmentation (MacArthur and Wilson 1967; Diamond 1975). Nonetheless, other measures of community structure, such as community composition, trophic organization, species persistence, and species residency, may better inform how fragmentation affects biotic communities, even when species richness per se is not altered by fragmentation (Robinson et al. 1992; Haddad et al. 2015).

- As habitat loss results in changes in both the amount and configuration of habitat (e.g., decreased patch size, increased patch isolation, and increased edge area), fragmentation-mediated processes cause generalizable responses at the population, community, and ecosystem levels. These include decreased residency within and movement among fragments, reduced species richness across taxonomic groups, and decreased nutrient retention (Haddad et al. 2015). By comparing findings across multiple landscape-scale fragmentation experiments, one can partition effectively the relative influence of increasing habitat loss, patch isolation, and edge influence on different community and ecosystem attributes (Haddad et al. 2015), and potentially distinguish generalizable consequences of fragmentation from more idiosyncratic, system-specific responses.

S. E. Russo

School of Biological Sciences, University of Nebraska-

Lincoln, Lincoln, NE 68588, USA

D. S. Wilcove

Woodrow Wilson School of Public and International

Affairs, Princeton University, Princeton, NJ 08544, USA

D. S. Wilcove

Department of Ecology and Evolutionary Biology,

Princeton University, Princeton, NJ 08544, USA

J. Wu

School of Sustainability, Arizona State University, Tempe, AZ 85287, USA 
- Area and isolation effects encompass a variety of ecological processes that can complicate our understanding of fragmentation. For example, reductions in patch size and increases in edgeaffected area can influence local ecosystem processes indirectly through microclimatic effects. To make results more generalizable, studies should decompose area and isolation effects into direct, ecologically relevant, mechanistic drivers such as microclimate, local matrix quality, and vulnerability to stochastic events (e.g., Laurance et al. 2011).

\section{Remaining questions and challenges}

Despite the progress made in formalizing fragmentation science, significant questions remain.

Local community-level dynamics

How do conditions at the time of fragmentation impact community structure and dynamics?

Historically the term fragmentation has been used to describe the ecological changes arising from two different landscape contexts. The first of these are relaxing systems - those intact at the time of fragmentation and which are now relaxing to few species and diminished ecosystem function (e.g., Laurance et al. 2011). In contrast, assembling systems are those in which successional processes occur within spatially distinct patches across a denuded landscape (e.g., Cook et al. 2005). Most studies have focused on communities that were intact at the time of fragmentation, losing species following the fragmentation event. Relatively few studies have focused on the impacts of habitat fragmentation on community assembly (e.g., Simberloff and Wilson 1970; Robinson et al. 1992). For instance, priority effects (Fukami 2015) and a combination of deterministic and stochastic processes may influence the trajectory of community assembly in fragmented systems (Norden et al. 2015). Patterns of beta diversity can be altered by fragmentation overlaying successional dynamics (Alexander et al. 2012). While the processes of assembly and relaxation do share some generalizable effects (Haddad et al. 2015, discussed above), we do not fully understand the ways in which these systems converge and diverge from each other, creating a primary source of confusion within the study of fragmentation.

What factors affect the relative balance between topdown and bottom-up processes in fragmented landscapes?

Community ecologists have long recognized that both top-down (predator-mediated) and bottom-up (producer-mediated) processes can influence community composition. However, our understanding of how topdown and bottom-up dynamics might interact across geographic space is limited (Gripenberg and Roslin 2007), although it is clear that spatial factors such as patch size could potentially impact the strength of trophic cascades (Terborgh 2010). Fragmented habitats present an excellent platform for examining the interaction between these forces over a variety of spatial scales.

How do the processes of dispersal and ecological filtering-exclusion due to the effects of environmental and biotic conditions-interact to structure biodiversity?

Although both dispersal- and niche-mediated mechanisms affect community assembly, the importance of the interaction between these processes in highdiversity communities is still largely unknown (Myers and Harms 2011). Fragmentation studies can be used to address this issue as well, especially when fragmentation eliminates some of the key players in biotic interactions such as mutualism and competition.

How does fragmentation predictably and consistently alter the variability of local biophysical conditions?

Large-scale experiments show that fragmentation has significant, unexpected effects on local biophysical conditions. For example, the Biological Dynamics of Forest Fragments Project of Manaus, Brazil finds that relatively unimportant drivers in intact systems can come to dominate fragmented systems. Examples include increased wind shear in tropical forest fragments (Laurance et al. 2011), and reduced fire frequency, in prairie systems (Leach and Givnish 1996). We need further work on altered disturbance 
regimes, especially focusing on the integration of patch shape and matrix characteristics, to generalize these results across landscapes and disturbance regimes. The inclusion on micro-climatic changes in studies of fragmented landscapes may also provide new insights into the mechanisms behind changes in community composition.

How quickly does evolutionary adaptation in fragmented habitats occur? How does this evolutionary adaption affect species coexistence and community assembly in fragmented habitats?

Recent work has shown that evolutionary changes can operate on ecological time scales. Local adaptations, whether in the form of evolutionary change or phenotypic plasticity, may alter the environmental selective pressures that control community assembly (Schoener 2011). Fragmentation research should play a key role in quantifying the speed of this adaptation to local conditions and how these adaptations alter species coexistence and community assembly.

Do smaller patches become "stuck" in successional stasis? If so, does this successional heterogeneity between larger and smaller patches alter the ability of biodiversity to recover from further perturbations at the landscape scale?

From the early twentieth century, ecologists have suspected that habitat fragmentation can alter successional trajectories, with smaller patches affected more greatly than larger ones (Clements 1936). Cook et al. (2005) report that succession towards woody vegetation occurs more slowly on small fragments, and Connell and Slatyer (1977) suggest that succession should reflect the interaction of disturbance intensity and size of the area being disturbed. Yet understanding the relationship between fragmentation and succession is largely unexplored.

How quickly and effectively can management actions mitigate declining numbers of species and diminished ecosystem functions following fragmentation?

The effects of habitat fragmentation on populations, communities, and ecosystems can take years to decades before becoming apparent, suggesting that patches will continue to lose species and see declines in ecosystem functions for considerable time periods (e.g., Brooks et al. 1999; Collins et al. 2009). Our ability to reduce the loss of species and functions during this period of decline merits investigation.

How does fragmentation impact population dynamics at the species level? How do these dynamics alter the relative probabilities of extirpations and recolonization?

Though traditional island biogeography is based on the probability of species extirpations and colonizations, it does not make predictions about how habitat fragmentation will affect the population dynamics of individual species. Therefore, metapopulation models based upon occupancy (presence/absences) have provided the frameworks generally used to study the impacts of fragmentation at the species level. From their very inception (Levins 1969, 1970), these frameworks have largely ignored the details of intra-patch population dynamics (Gilpin and Hanski 1991). Yet, such local population dynamics underlie the local extirpations and (to a lesser extent) recolonizations of individual species within and among patches. Thus, they represent a critical, if largely unstudied, component in applying fragmentation research at the species level. For instance, do time-series of abundances for a focal species typical show clear signals of population decline in fragments, long before extinction actually occurs?

Landscape-scale dynamics

How do edge contrast and matrix quality change metacommunity dynamics?

The relative similarity or dissimilarity between habitat and non-habitat areas ("edge contrast") and matrix quality in an absolute sense can affect both individual organisms and material fluxes (Ricketts 2001; Prevedelo and Vieira 2010). Further, fragmented landscapes can allow for the persistence of a metacommunity, or a set of local communities that are connected through the processes of dispersal and extirpation (Gilpin and Hanski 1991; Wilson 1992; Holyoak et al. 2005). Studies have not considered how the interaction of these mechanisms affects metacommunity dynamics in terms of patch-specific dispersal, colonization, and extirpation probabilities of species, particularly in the context of fragmentation. 
How does habitat fragmentation alter relationships between biodiversity and ecosystem functioning across multiple scales?

There is broad recognition that fragmentation affects both biodiversity and ecosystem functioning (Haddad et al. 2015). Our knowledge of biodiversity-ecosystem functioning relationships suggests that local loss of biodiversity causes a local loss of function. These expectations extrapolate from a research base in which community biodiversity was experimentally altered in a randomized design (Loreau et al. 2001; Hooper et al. 2005), rather than altered by the non-random species losses that fragmentation causes (e.g., Ewers and Didham 2006). The effects of fragmentation on relationships between biodiversity and functioning merit further study.

\section{How will the local microclimatic effects}

of fragmentation interact with climate change on the individual, population, community, ecosystem, and landscape levels?

Fragmentation can change the microclimate at both local and regional scales (e.g., Young and Mithchell 1994; Didham and Lawton 1999; Laurance et al. 2011). These fragmentation-based climatic changes may interact with other types of anthropogenic climate change, further influencing biodiversity through unstudied interactions between the two drivers.

\section{What is the appropriate spatial scale for studying} the ecological impacts generally attributed to habitat fragmentation?

The ecological impacts of fragmentation occur across a variety of spatial scales. For example, edge effects affect populations and communities on within-patch scales. Dispersal acts on both within-patch and between-patch scales, and changes in ecosystem services occur across multiple scales. The literature does not well establish these scaling relationships as fragmentation studies have rarely taken a hierarchical, multiple-scale approach (Didham et al. 2012).

\section{The role of fragmentation experiments}

Field-based fragmentation experiments are critical in expanding our understanding of habitat fragmentation.
Ranging in spatial scale from $2 \times 10^{-7}$ ha to 100 ha, the most commonly recognized fragmentation experiments cover a broad range of ecological communities (Fig. 1; Haddad et al. 2015). In contrast to observational studies, these projects have careful, a priori, experimental designs with significant levels of replication and known initial conditions, allowing for powerful inferences. Few however approach the scale at which contemporary land management and conservation planning must address fragmentation.

One challenge is to bridge the gap between scales feasible for direct experimental manipulation, and larger scales which are the domain of conservation, restoration, and management. Large-scale infrastructure projects can at times provide inadvertent, unplanned experiments which can be utilized to fill this gap in scales. For example, in Venezuela, Professor John Terborgh creatively utilized the creation of Lago Guri, a large $\left(>4000 \mathrm{~km}^{2}\right)$ man-made hydroelectric lake dotted with hundreds of forested islands, to demonstrate the dramatic importance of trophic cascades in tropical forest (Terborgh et al. 2001). Unfortunately, the draining of the lake destroyed the integrity of the study, and combined with political uncertainties, research there is not ongoing.

Another promising large-scale, unplanned experiment, comparable in some ways to Lago Guri, which can fill the gap between standard fragmentation experiments and large spatial scales is the ongoing project at Thousand Island Lake (TIL). Formed in 1959 TIL is a large, man-made lake in Chun'an County of Zhejiang Province, China. TIL has total water surface of approximately $580 \mathrm{~km}^{2}$ and 1078 land-bridge islands when the maximum water level (108 m.a.s.1.) (Figure 1; Wang et al. 2009). During dam construction, primary forests in the region were selectively or clear-cut with organized logging during the "Great Leap Forward." This resulted in near complete deforestation before the lake's inundation. Airplanes then sowed native pines, possibly affecting soil $\mathrm{pH}$ or causing allelopathy that could have lasting effects on regional biotas. This region is now protected as one of the largest national parks in China. The majority of the islands (erstwhile hilltops) have not experienced significant human disturbance since 1962. In concert, these reasonably consistent initial conditions combined with a history of ecological monitoring and the opportunity for very high levels of 


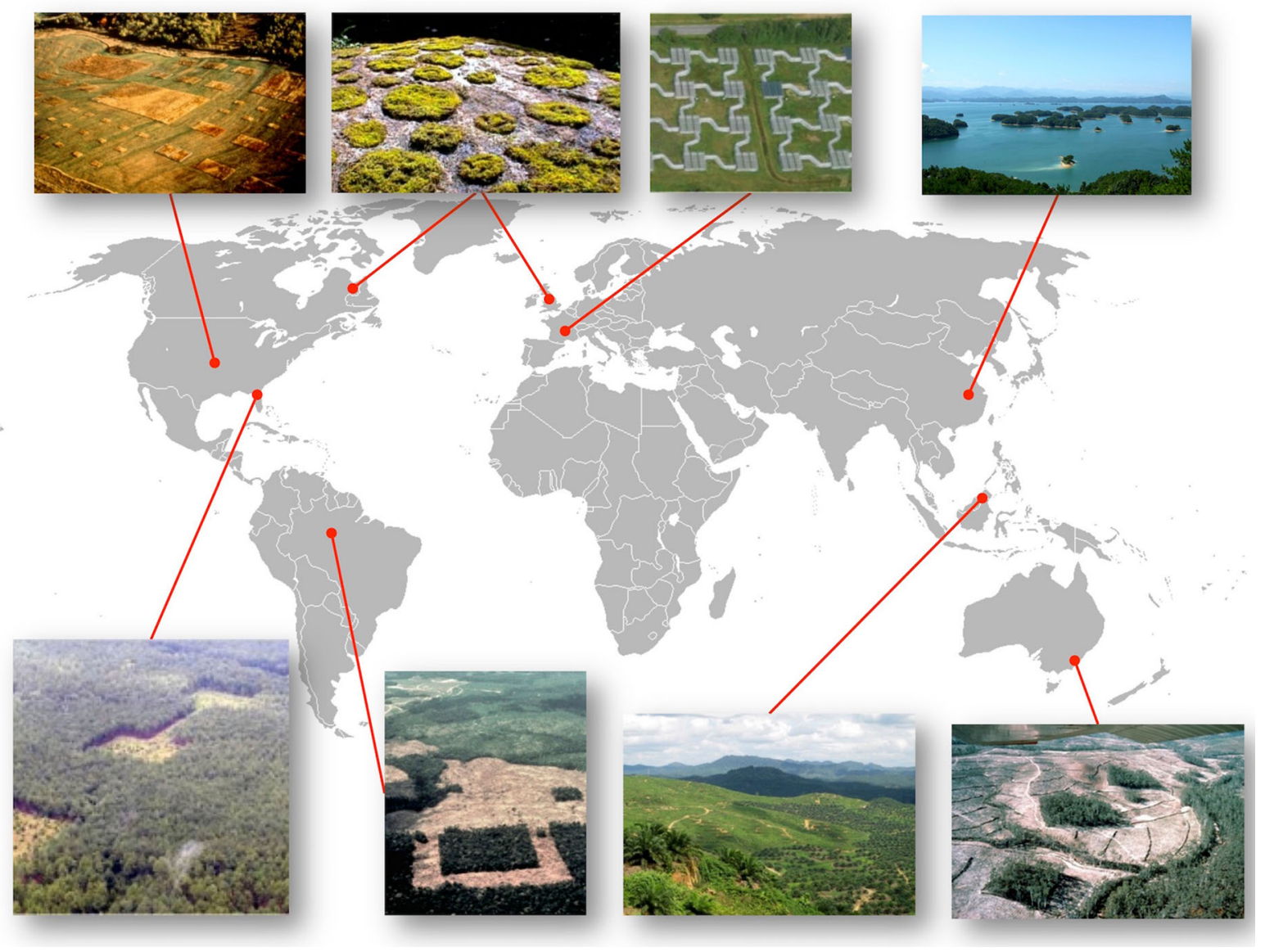

Fig. 1 Map of long-term fragmentation experiments as identified in Haddad et al. (2015) with the addition of Thousand Island Lake, clockwise from top-left: 1 Kansas Fragmentation Project (KFP). Located in Kansas, USA, KFP is an experimentally fragmented prairie ecosystem, focusing on the impacts of fragmentation on community assembly and successional processes. 2 Moss fragmentation experiments (MFE). Consisting of a wide range of projects carried out simultaneously in both the UK and Canada, MFE includes both field and laboratory experiments, which have focused on a broad array of processes, including fragmentation per se, corridor effectiveness, and the interactions between fragmentation and climate change. 3 Metatron. Perhaps the most technically complex and flexible fragmentation experiment, Metatron, located in south central France, consists of independent patches which can be connected or disconnected via experimentally controlled corridors, allowing for the study of multiple landscape configurations. 4 Thousand Island Lake (TIL). Described in detail in the text, TIL combines both community assembly and relaxation

replication, allow the TIL system to avoid many of the pitfalls that plague other "natural" fragmentation experiments. This history also ensures that TIL will combine aspects of relaxing and assembling ecosystems, in that the original understory community was processes across more than 1000 remnant islands. 5 Wog Wog Habitat Fragmentation Experiment (WWHFE). Located in Southeastern Australia, WWHFE was designed to study the effects of habitat fragmentation on biological diversity in an Eucalyptus forest. 6 Stability of Altered Forest Ecosystems (SAFE) Project. Located in the rainforests of Malaysian Borneo, SAFE is composed of multiple projects that investigate how forest modification gradients (e.g., land use and cover patterns) and forest fragmentation affect biodiversity, ecological processes, and waterways. 7 Biological Dynamics of Forest Fragments Project (BDFFP). Located in the Brazilian Amazon, BDFFP is the world's largest and longest-running habitat fragmentation experiment, conducting a wide range of forest fragmentation effects on biodiversity and ecosystem processes. 8 Savannah River Site Corridor Experiment (SRSCE). Located in South Carolina, USA, SRSCE was designed to study the effects of corridors on plant and animal dispersal, population persistence, and biodiversity in a managed forest

not directly removed, and the removal of trees would set into motion successional dynamics as recolonization occurs from external seed sources.

Studies at TIL have already provided the building blocks necessary to answer many of the questions 
proposed above, providing insights into the recovery patterns of avian, mammalian, reptilian, and plant communities in fragmented landscapes. A suite of studies, focusing on both plant and animal communities, have shown that island area plays the dominant role in controlling community recovery on TIL's islands. On the species and gene levels, plant, bird, snake, and small mammal communities have clear relationships with island area, but not island isolation (Wang et al. 2010, 2011, 2012b; Hu et al. 2011; Zhang et al. 2012; Ding et al. 2013; Si et al. 2014, 2015a; Su et al. 2014; Yuan et al. 2015). There are some notable exceptions to the trend of area effects dominating isolation effects (e.g., Wang et al. 2012a; Yu et al. 2012; Peng et al. 2014). That said, when taken as a whole these results suggest that patch area may be a more significant factor in community assembly than patch isolation in this system. Ongoing research is underway to dissect the specific mechanisms by which this process occurs (e.g., Hu et al. 2015; Si et al. 2015b).

The opportunity for comparison between TIL to other large scale fragmentation experiments is promising. Because the communities of TIL are primarily assembling, direct comparisons to other assembling communities such as the Kansas Fragmentation Experiment (e.g., Cook et al. 2005) could provide insights into whether successional processes in fragmented landscapes are consistent across biomes. Used together, systems in which matrix quality remains constant can compare to large-scale experiments in which matrix quality varies, such as the Biological Dynamics of Forest Fragments Project (e.g., Laurance et al. 2011), to address questions concerning edge contrast. Naturally, there are many other opportunities for comparison. We expect the TIL project to play a critical role in fragmentation research over the coming decades, while also proving a platform for international collaborations.

Fragmentation studies in the past have enabled us to understand a wide range of effects of habitat loss and fragmentation on biodiversity and ecological processes, but fundamental questions remain. These questions span spatial, temporal, and organizational scales, and they necessitate new approaches and techniques. With a focus on identifying ecologically relevant drivers, we are confident that answering these questions will provide scientists and practitioners with the scientific basis and tools necessary to promote biodiversity and landscape sustainability.
Acknowledgments The workshop was funded by the Zhejiang Association for Science and Technology, the Ecological Society of Zhejiang Province, the Botanical Society of Zhejiang Province, the People's Government of Chun' an County, the Thousand Island Lake National Forest Park of Zhejiang and the National Natural Science Foundation of China (Grant Number 31210103908). National Natural Science Foundation of China (Grant Numbers 31210103908, 31361123001 and 31200413) and the US National Science Foundation (Grant Numbers DEB-1342754 and DEB1342757) have also supported the projects in the Thousand Island Lake.

\section{References}

Alexander HM, Foster BL, Ballantyne F IV, Collins CD, Antonovics J, Holt RD (2012) Metapopulations and metacommunities: combining spatial and temporal perspectives in plant ecology. J Ecol 100:88-103

Brooks TM, Pimm SL, Oyugi JO (1999) Time lag between deforestation and bird extinction in Tropical Forest Fragments. Conserv Biol 13:1140-1150

Clements FE (1936) Nature and structure of the climax. J Ecol 24:252-284

Collinge SK (2009) Ecology of fragmented landscapes. Johns Hopkins University Press, Baltimore

Collins CD, Holt RD, Foster BL (2009) Patch size effects on plant species decline in an experimentally fragmented landscape. Ecology 90:2577-2588

Connell JH, Slatyer RO (1977) Mechanisms of succession in natural communities and their role in community stability and organization. Am Nat 111:1119-1144

Cook WM, Yao J, Foster BL, Holt RD, Patrick LB (2005) Secondary succession in an experimentally fragmented landscape: community patterns across space and time. Ecology 86:1267-1279

Diamond JM (1975) The island dilemma: lessons of modern biogeographic studies for the design of natural reserves. Biol Conserv 7:129-146

Didham RK, Lawton JH (1999) Edge structure determines the magnitude of changes in microclimate and vegetation structure in tropical forest fragments. Biotropica 31:17-30

Didham RK, Kapos V, Ewers RM (2012) Rethinking the conceptual foundations of habitat fragmentation research. Oikos 121:161-170

Ding Z, Feeley KJ, Wang Y, Pakeman RJ, Ding P (2013) Patterns of bird functional diversity on land-bridge island fragments. J Anim Ecol 82:781-790

Ewers RM, Didham RK (2006) Confounding factors in the detection of species responses to habitat fragmentation. Biol Rev 81:117-142

Fahrig L (2003) Effects of habitat fragmentation on biodiversity. Ann Rev Ecol Syst 34:487-515

Fukami T (2015) Historical contingency in community assembly: integrating niches, species pools, and priority effects. Ann Rev Ecol Evol Syst 46:1-23

Gilpin ME, Hanski IA (1991) Metapopulation dynamics: empirical and theoretical investigations. Academic Press, London

Gripenberg S, Roslin T (2007) Up or down in space? Uniting the bottom-up versus top-down paradigm and spatial ecology. Oikos 116:181-188 
Haddad NM, Brudvig LA, Clobert J, Davies KF, Gonzalez A, Holt RD, Lovejoy TE, Sexton JO, Austin MP, Collins CD, Cook WM, Damschen EI, Ewers RM, Foster BL, Jenkins $\mathrm{CN}$, King AJ, Laurance WF, Levey DJ, Margules CR, Melbourne BA, Nicholls AO, Orrock JL, Song DX, Townshend JR (2015) Habitat fragmentation and its lasting impact on Earth's ecosystems. Sci Adv 1:e1500052

Holyoak M, Leibold MA, Holt RD (2005) Metacommunities: spatial dynamics and ecological communities. University of Chicago Press, Chicago, pp 1-31

Hooper DU, Chapin FS III, Ewel JJ, Hector A, Inchausti P, Lavorel S, Lawton JH, Lodge DM, Loreau M, Naeem S, Schmid B, Setälä H, Symstad AJ, Vandermeer J, Wardle DA (2005) Effects of biodiversity on ecosystem functioning: a consensus of current knowledge. Ecol Monogr 75:3-35

Hu G, Feely KJ, Wu J, Xu GF, Yu MJ (2011) Determinants of plant species richness and patterns of nestedness in fragmented landscapes: evidence from land-bridge islands. Landsc Ecol 26:1405-1417

Hu G, Feeley KJ, Yu M (2015) Configuration of fragmented habitat drives plant community assembly processes across plant life stages. J Biogeogr (in review)

Laurance WF, Camargo JLC, Luizao RCC, Laurance SG, Pimm SL, Bruna EM, Stouffer PC, Williamson GB, BenitezMalvido J, Vasconcelos HL, Van Houtan KS, Zartman CE, Boyle SA, Didham RK, Andrade A, Lovejoy TE (2011) The fate of Amazonian forest fragments: a 32-year investigation. Biol Conserv 144:56-67

Leach MK, Givnish TJ (1996) Ecological determinates of species loss in remnant prairies. Science 237:1555-1558

Levins R (1969) Some demographic and genetic consequences of environmental heterogeneity for biological control. Bul Entomol Soc Am 15:237-240

Levins R (1970) Extinction. In: Gesternhaber M (ed) Some mathematical problems in biology. American Mathematical Society, Providence, pp 77-107

Loreau M, Naeem S, Inchausti P, Bengtsson J, Grime JP, Hector A, Hooper DU, Huston MA, Raffaelli D, Schmid B, Tilman D, Wardle DA (2001) Biodiversity and ecosystem functioning: current knowledge and future challenges. Science 294:804-808

MacArthur RH, Wilson EO (1967) The theory of island biogeography. Princeton University Press, Princeton

Myers JA, Harms KE (2011) Seed arrival and ecological filters interact to assemble high-diversity plant communities. Ecology 92:676-686

Norden N, Angarita HA, Bongers F, Martínez-Ramos M, Granzow-de la Cerda I, van Breugel M, Lebrija-Trejos E, Meave JA, Vandermeer J, Williamson GB, Finegan B, Mesquita R, Chazdon RL (2015) Successional dynamics in neotropical forests are as uncertain as they are predictable. Proc Natl Acad Sci USA 112:8013-8018

Peng S, Hu G, Yu M (2014) Beta diversity of vascular plants and its influencing factors on islands in the Thousand Island Lake. Acta Ecol Sinica 34:3866-3872 (in Chinese with English abstract)

Prevedelo JA, Vieira MV (2010) Does the type of matrix matter? A quantitative review of the evidence. Biodivers Conserv 19:1205-1223

Ricketts TH (2001) The matrix matters: effective isolation in fragmented landscapes. Am Nat 158:87-99
Robinson GR, Holt RD, Gaines MS, Hamburg SP, Johnson ML, Fitch HS, Martinko EA (1992) Diverse and contrasting effects of habitat fragmentation. Science 257:524-526

Schoener TW (2011) The newest synthesis: understanding the interplay of evolutionary and ecological dynamics. Science 331:426-429

Si X, Pimm SL, Russell GJ, Ding P (2014) Turnover of breeding bird communities on islands in an inundated lake. J Biogeogr 41:2283-2292

Si X, Baselga A, Ding P (2015a) Revealing beta-diversity patterns of breeding bird and lizard communities on inundated land-bridge islands by separating the turnover and nestedness components. PLoS One 10:e0127692

Si X, Baselga A, Leprieur F, Song X, Ding P (2015b) Selective extinction drives taxonomic and functional alpha and beta diversities in island bird assemblages. J Anim Ecol (accepted)

Simberloff DS, Wilson EO (1970) Experimental zoogeography of islands: a 2 year record of colonization. Ecology 51:934-937

Su X, Yuan J, Hu G, Xu G, Yu M (2014) Edge effect of the plant community structure on land-bridge islands in the Thousand Island Lake. Chin J Appl Ecol 25:77-84 (in Chinese with English abstract)

Terborgh J (2010) The trophic cascade on islands. In: Losos JB, Ricklefs RE (eds) The theory of island biogeography revisited. Princeton University Press, Princeton, pp 116-142

Terborgh J, Lopez L, Nuñez P, Rao M, Shahabuddin G, Orihuela G, Riveros M, Ascanio R, Adler GH, Lambert TD, Balbas L (2001) Ecological meltdown in predator-free forest fragments. Science 294:1923

Wang Y, Zhang J, Feeley KJ, Jiang P, Ding P (2009) Lifehistory traits associated with fragmentation vulnerability of lizards in the Thousand Island Lake, China. Anim Conserv 12:329-337

Wang Y, Bao Y, Yu M, Xu G, Ding P (2010) Nestedness for different reasons: the distributions of birds, lizards and small mammals on islands of an inundated lake. Divers Distrib 16:862-873

Wang R, Compton SG, Chen XY (2011) Fragmentation can increase spatial genetic structure without decreasing pollen-mediated gene flow in a wind-pollinated tree. Mol Ecol 20:4421-4432

Wang Y, Lane A, Ding P (2012a) Sex-biased dispersal of a frog (Odorrana schmackeri) is affected by patch isolation and resource limitation in a fragmented landscape. PLoS One 7(10):e47683

Wang Y, Wang X, Ding P (2012b) Nestedness of snake assemblages on islands of an inundated lake. Curr Zool 58:828-836

Wilson DS (1992) Complex interactions in metacommunities, with implications for biodiversity and higher levels of selection. Ecololgy 73:1984-2000

Wu JG (2013) Key concepts and research topics in landscape ecology revisited: 30 years after the Allerton Park workshop. Landsc Ecol 28:1-11

Wu JG, Loucks OL (1995) From balance of nature to hierarchical patch dynamics: a paradigm shift in ecology. Q Rev Biol 70:439-466

Young A, Mithchell N (1994) Microclimate and vegetation edge effects in a fragmented podocarp-broadleaf forest in New Zealand. Biol Conserv 67:63-72 
Yu M, Hu G, Feeley KJ, Wu J, Ding P (2012) Richness and composition of plants and birds on land-bridge islands: effects of island attributes and differential responses of species groups. J Biogeogr 39:1124-1133

Yuan N, Comes HP, Cao YN, Guo R, Zhang YH, Qiu YX (2015) A comparative study on genetic effects of artificial and natural habitat fragmentation on Loropetalum chinense
(Hamamelidaceae) in Southeast China. Heredity 114:544-551

Zhang X, Shi MM, Shen DW, Chen XY (2012) Habitat loss other than fragmentation per se decreased nuclear and chloroplast genetic diversity in a monoecious tree. PLoS One 7:e39146 